\title{
Urban-rural transformation in relation to cultivated land conversion in China: Implications for optimizing land use and balanced regional development
}

\author{
Yuheng $\mathrm{Li}^{\mathrm{a}, *}$, Yurui $\mathrm{Li}^{\mathrm{a}}$, Hans Westlund ${ }^{\mathrm{b}}$, Yansui Liu ${ }^{\mathrm{c}}$ \\ a Institute of Geographic Sciences and Natural Resources Research, Chinese Academy of Sciences, Beijing 100101, China \\ ${ }^{\mathrm{b}}$ Department of Urban Planning and Environment, School of Architecture and Built Environment, KTH Royal Institute of Technology, Stockholm, Sweden \\ ${ }^{\mathrm{c}}$ College of Resources Science and Technology, Beijing Normal University, Beijing, China
}

\section{A R T I C L E I N F O}

\section{Article history:}

Received 18 June 2014

Received in revised form 17 March 2015

Accepted 7 April 2015

\section{Keywords:}

Urban-rural transformation

Urbanization

Land conversion

Bohai Rim region

China

\begin{abstract}
A B S T R A C T
The paper aims to investigate land conversion as a result of urban-rural transformation in the Chinese context. Theoretical analysis and empirical study of the Bohai Rim region find strong connections between the land conversion rates and urban-rural transformation intensity in the period 2000-2010. Rapid land conversion normally takes place in counties/districts of low initial level of urban-rural transformation. However, places of high initial socioeconomic level and low transformation intensity would experience slow land conversion. The different land conversion rates in relation to urban-rural transformation intensity are mainly attributed to the China's land quotas distribution system which is subjective and administrative. The study highlights the implementation of land quotas distribution system based on differences to improve the land distribution efficiency and achieve balanced regional development in China.
\end{abstract}

@ 2015 Elsevier Ltd. All rights reserved.

\section{Introduction}

Land conversion from its natural state to human use is the most permanent and often irreversible effect of human interaction with the natural environment (Jolly and Torrey, 1993). The transformation of human activities in turn, exerts further impact on land use change (Mitsuda and Ito, 2011). During the past decades, China has undergone intense transformation within the globalized context-that is, economic transformation from centrally-controlled economy to market-oriented economy, social transformation from a closed and traditional society to an open and modernized industrial and urban society (Li, 2011a). What it is seen is the large-scale rural-urban migration, rapid adjustments of employment structure and industrial structure in both urban and rural areas (Li, 2012a). At the meantime, the transformation has been accompanied by rapid land-use changes and modifications which swept the whole China (Ding, 2003; Lin, 2010; Liu et al., 2014a,b). In the period 1996-2008, the built-up land in both the cities and the countryside of China has grown from 29.6 million ha

\footnotetext{
* Corresponding author. Tel.: +86 1064889034 ; fax: +861064857065

E-mail address: liyuheng@igsnrr.ac.cn (Y. Li).
}

to 33.1 million ha while arable land decreased by 8.4 million ha in the same period ${ }^{1}$.

Basically, land conversion for non-agricultural use has effectively supported China's socioeconomic transformation when the country experienced fast urbanization and industrialization ever since 1978. However, unlike the excessive urbanization in Latin American and Caribbean countries, and over suburbanization in certain developed countries, urbanization in China was characterized as excessive land conversion (Liu, 2006; Peng, 2008; Li et al., 2014). In the period 2005-2010, the Chinese government approved land requisition of 2.16 million ha, an annual land requisition of 361,000 ha according to the Ministry of Land and Resources (2005-2010). The built-up area in urban China has increased by $50 \%$ since 2000 , however, urban population growth is only $26 \%$ in the period 2000-2009 (National Bureau of Statistics of China, 2010). This indicates an over speeded land conversion and lagging urbanization growth in China in the transformation era. As for the villages, the large-scale transfer of peasants to non-agricultural sectors in cities has aggravated the "rural hollowing" problem in China.

\footnotetext{
1 The data is compiled according to the detailed land-use survey data at the county level, provided by the ministry of land and resources in each Province (city) in the period 1996-2011.
} 
This problem finally generates the related effects of a decreasing rural population and increasing residential land area. In the period 1996-2008, the number of rural migrants amounted to 135 million in China, nevertheless, rural built land increased 235,000 ha (Liu et al., 2014a,b).

Such inconsistence between land conversion and China's current urban-rural transformation raised concerns about food security (Yang and Li, 2000), urban sprawl (Johnson, 2001), open space loss (Wasilewski and Krukowski, 2004), arable land protection (Li et al., 2014) and environmental degradation (Zhang et al., 2007; Li et al., 2010a,b). Being a country of large population and little per capita land the Chinese government should be alert to land conversion within its transformation process. How does urban-rural transformation connect with land conversion? How does land conversion respond to the transformation process? What are the policy implications to effectively supervise land conversion and protect arable land? The paper aims at investigating land conversion as a result of the current transformation in China.

\section{Research base: Urban-rural transformation and land conversion}

\section{The aspects of urban-rural transformation}

Historically, there exist rigid distinctions between "urban" and "rural". For quite a long time, urban and rural areas were treated as two separate issues with little consideration of their interrelations (Roberts, 1978; Harris, 1982). It is, however, commonly understood that strong mutual linkages exist between urban and rural areas, through resource flows of people, capital, goods, information and technology (Tacoli, 1998; Li, 2012b). In Asia's developing countries, the encouragement of urbanization and structural shifts to industrial and service sectors have been the favored development strategies during the past 30 years (World Bank, 1993; White, 1998). In this process, urban and rural areas are shifting from being isolated parts to undergoing rapid transformation with strong mutual linkages.

China has for a long time, maintained the urban-rural dual structure by implementing urban biased policies which strongly isolated the mutual linkages between these two parts (Li, 2011b). When the ever enlarging urban-rural disparities endangered the socioeconomic stability, the Chinese government began to promote rural development by creating rural favored policies and intensifying the mutual linkages between cities and countryside.

As a result, dramatic transformation occurs in China which has experienced increasing agricultural productivity, rural-urban migration, industrialization and urbanization which shaped the growth of urban and rural areas simultaneously. For one thing, cities grow rapidly due to the flourishing economy and large-scale rural immigrants; for another thing, rural economy inclines to depend on cities and becomes diversified. Meanwhile, there is also the urban civilization spreading and diffusing to villages. Finally, by way of such transformation, urban and rural areas in China are closely linked with each other, and gradually approach the integration status.

\section{Land conversion within the transformation process in China}

Generally, the urban-rural transformation, because of the globalization, institutional adaptations and unique socioeconomic conditions in China has highly accelerated the process of land conversion. First and foremost, the growth of cities has been dominated by the state-led replacement of rural space by urban space during the past decades. This is accomplished through the creation of provincial level municipalities, the expansion of existing municipalities, the reclassification of counties to municipalities and the creation of new urban spaces, as well as the amalgamation of townships (McGee, 2008). By way of reshaping the administrative space, urban areas extended their spatial control over former rural areas. As Table 1 shows, large cities have been growing steadily since 1990 while many small cities have grown into medium cities in China.

When the huge peasants' influx generate great land demand for housing, infrastructure and public spaces, local governments are pressed to expand the urban built-up land. Meanwhile, driven by the huge benefits from selling land for non-agricultural use, local governments are crazy about expropriating rural land into urban land. This also becomes the way of achieving major local revenues for most Chinese cities. As a result, the period 1996-2010 saw fast expansion of urban built-up land from 2.02 million ha to 4.01 million ha, and rapid arable land reduction from 130.04 million ha to 121.73 million ha.

Rural transformation in China is a hybrid and contested process (Long et al., 2012). It possesses changes that rural Europe used to experience during the early-to-mid twentieth century and rural restructuring in contemporary Europe (Cloke et al., 1997; Hoggart and Paniagua, 2001; Robinson, 2004; Woods, 2005, 2011). As a result, rural transformation driven by related policies induced tremendous land-use changes in rural China (Deng et al., 2009). The emerging 'rural hollowing' problem becomes serious in China in recent years. It indicates the communities which are experiencing depopulation and housing modernization that led to the abandonment of a significant number of properties, spread throughout the settlement (Liu et al., 2009; Long et al., 2009). During the past decade, the tendency of "outward expansion while inside hollowing, one family of more houses, building new houses without dismantling the old one, unused new houses" become aggravated in rural China (Long et al., 2012; Li et al., 2014).

When there is large amount of arable land converted for nonagricultural use, the "requisition-compensation balance of arable land" policy was implemented. The policy requests land compensation of same amount of requisitioned land so as to reduce arable land loss. Owing to the limited barren land, local governments are propelled to reclaim land by destroying forested and grassland, building dykes to reclaim land from rivers and lakes as well as reclaiming slopes which are ecologically fragile places. According to the second national land survey, tidal flat and marsh decreased by $10.7 \%$ and 10.67 million ha grassland was lost due to land reclamation and occupation that comparing with the first land survey $(1984-1997)^{2}$.

\section{Study area}

The Bohai Rim region is located in the Eastern China, covering the entire provinces of Beijing, Tianjin, Hebei, Liaoning and Shandong (Fig. 1). The administrative area of the region is $515,500 \mathrm{~km}^{2}$ which accounts for $5.4 \%$ of the land area of China. In 2013, there were 250.4 million people in the region, taking up $18.4 \%$ of the total population in mainland China.

The paper selects the Bohai Rim region as the study area for three reasons. First, the region acts as the third engine besides the Yangtze River Delta and the Zhujiang River Delta, stimulating the China's economy. In 2013, the GDP of the region amounted to 14.4 trillion Chinese Yuan, which shared one quarter in the Chinese GDP. Besides, per capita GDP of the region was 9241.8 US dollars, indicating an era of rapid urban-rural transformation in this area. Second, over $84 \%$ of the land in the region has been exploited and

\footnotetext{
2 http://money.163.com/13/1230/11/9HBBJP6D00254TI5.html.
} 
Table 1

Number of cities of different population size in China, 1990-2010.

\begin{tabular}{|c|c|c|c|c|c|c|}
\hline Urban system & Population size & 1990 & 1995 & 2000 & 2005 & 2010 \\
\hline \multirow[t]{5}{*}{ Large city } & $>10$ million & 0 & 0 & 0 & 1 & 6 \\
\hline & 5 million-10 million & 2 & 2 & 2 & 3 & 10 \\
\hline & 2 million-5 million & 7 & 9 & 11 & 17 & 37 \\
\hline & 1 million-2 million & 22 & 21 & 27 & 32 & 83 \\
\hline & $500,000-1$ million & 28 & 43 & 53 & 78 & 106 \\
\hline Medium city & $200,000-500,000$ & 117 & 192 & 218 & 243 & 253 \\
\hline Total number & & 176 & 267 & 311 & 374 & 495 \\
\hline Small city & $100,000-200,000$ & 291 & 373 & 352 & 287 & 162 \\
\hline Towns & $<100,000$ & 12,084 & 17,532 & 20,312 & 19,522 & 19,683 \\
\hline Total number & & 12,375 & 17,905 & 20,664 & 19,809 & 19,845 \\
\hline
\end{tabular}

Note: Data collects from the national census of various years.

used. In this process, arable land decreases rapidly while built-up land expands continuously. As a result, there is aggravated contradiction between limited auxiliary land resources and large land demand due to socioeconomic development. Third, huge differences exist among the well-developed super cities like Beijing, the rapidly growing industrial cities like Qian'an of Tangshan city, the traditional agricultural counties like Zaoqiang county of Hengshui city, and the Taihang Mountain region where the 'poverty belt' around Beijing and Tianjin is located. Thus, the Bohai Rim region suits the study which seeks diversified urban-rural transformation of different areal types.

\section{Materials and methods}

Generally, the relationship between land conversion and socioeconomic development follows the Environmental Kuznets Curve during certain time period. Li et al. (2014) proved such relationship in China in the period 2000-2009. Basically, in the primary stage of socioeconomic development, scale effects promote rapid increases in the land conversion rate. When the economic structure shifts from industries relying on intensive land inputs to a condition wherein less land-intensive industries dominate, the rate of land conversion starts to slow down at the middle development stage. Then, the technological progress at the mature development stage will help substitute large-scale land inputs with man-made resources. In this sense, we can conclude that the land conversion rate responds to the transformation process of different intensities at different development stages in China.
As illustrated in the above sections, the urban-rural transformation is a dynamic process which witnesses rural-urban population mobility and changes of employment and industrial structures in both urban and rural areas. For the study concern, Njegac and Toskic (1999) pointed out that urban-rural transformation generally consists of the morphological transformation (urbanization and employment of non-agricultural sectors) and functional transformation (development of non-agricultural industries). Thus, the paper uses the urbanization level, proportion of non-agricultural employment, proportion of non-agricultural output value to describe the morphological and functional features of urban-rural transformation at the county level in the study area.

The paper uses principal component analysis to transform correlated variables into a smaller number of uncorrelated variables called principal components. The data matrix will finally be compressed into fewer orthogonal components that are uncorrelated. The aggregative model was established according to the component coefficients, as follows:

Trans $_{i}=0.087 X_{1}+0.447 X_{2}+0.542 X_{3}$

where Trans $_{i}$ indicates the intensity of urban-rural transformation of county $i$ in the period 2000-2010, while $X_{1}, X_{2}$, and $X_{3}$ are the annual average changing rates of the urbanization level, proportion of non-agricultural employment, proportion of nonagricultural output value. According to the formula, the coefficients of the selected variables positively contribute to the intensity of

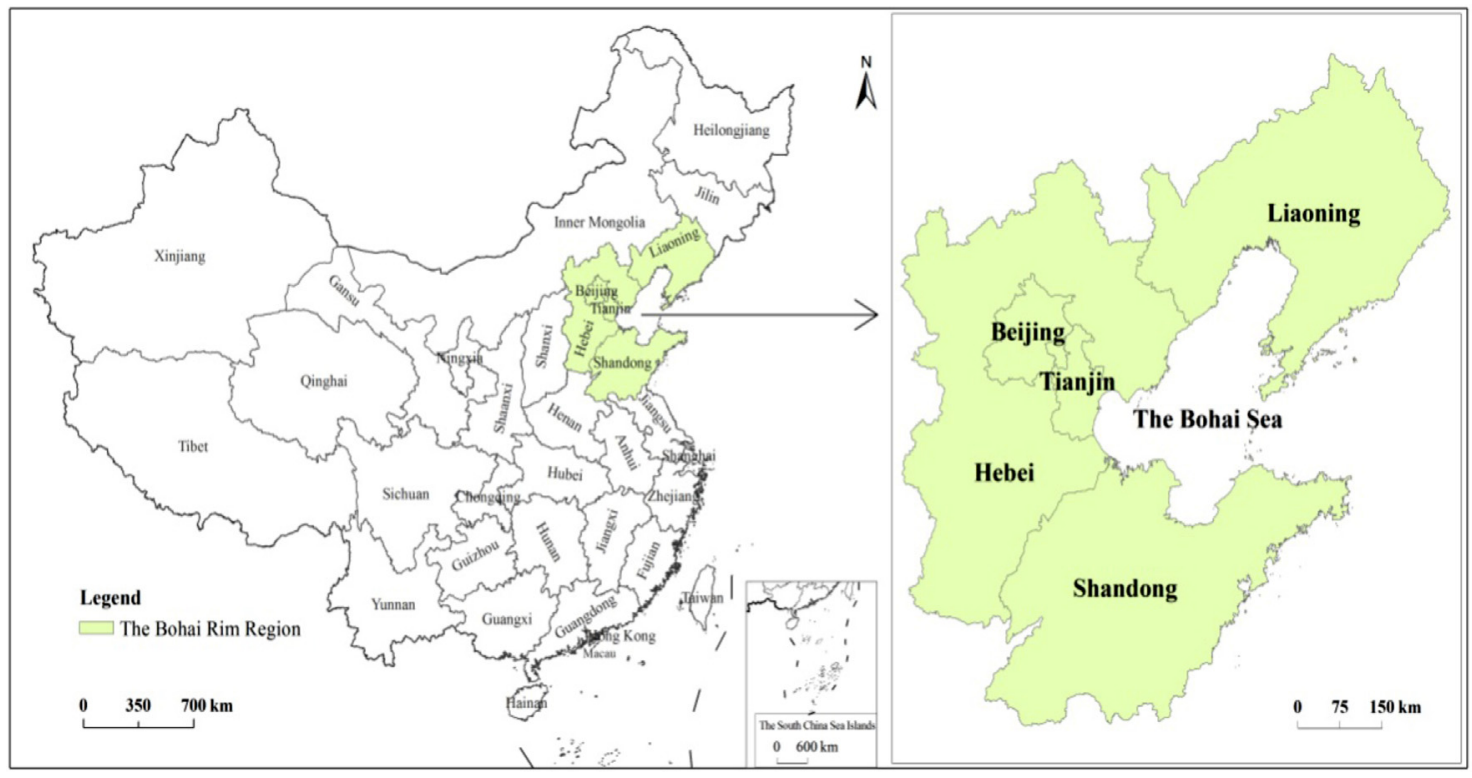

Fig. 1. The Bohai Rim region in China. 


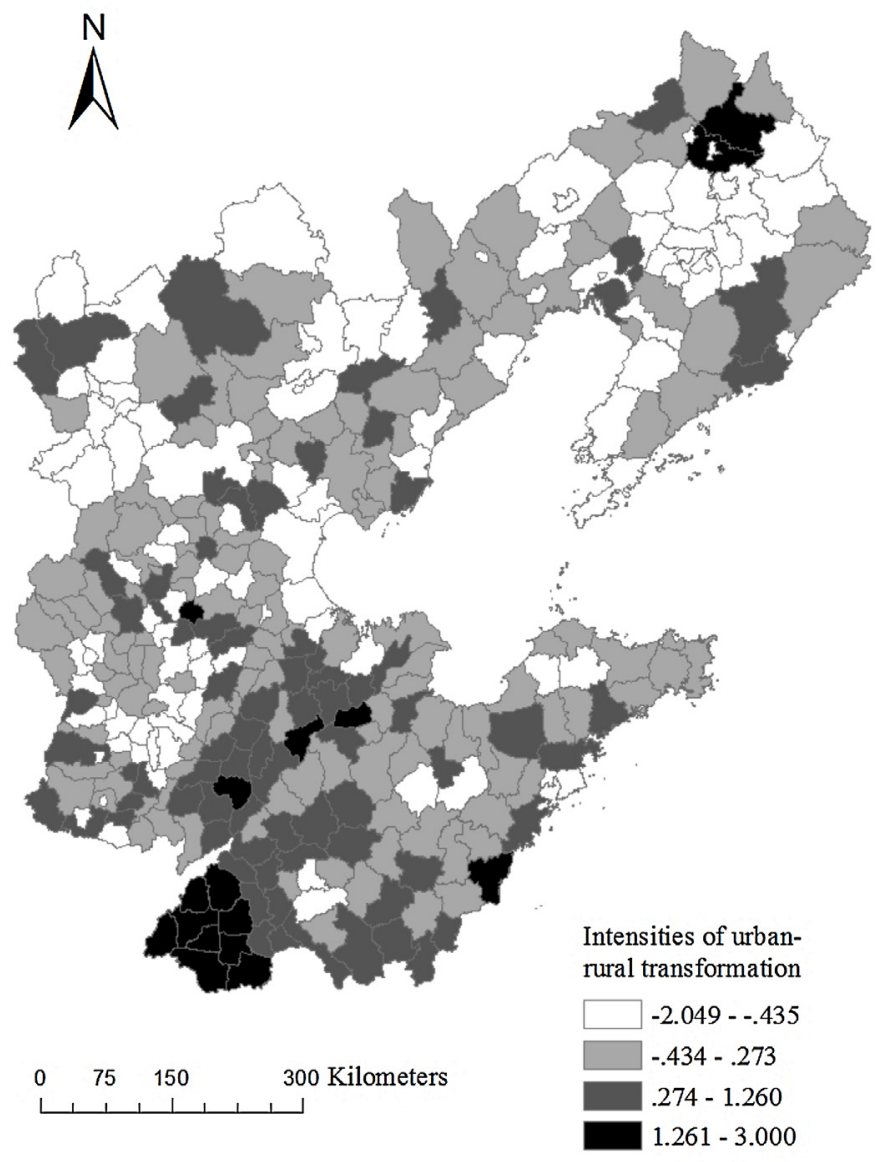

Fig. 2. The urban-rural transformation intensity in the Bohai Rim region, 2000-2010.

urban-rural transformation, and the proportion of non-agricultural output value is the main variable in the aggregative model.

To investigate the relationship between land conversion and urban-rural transformation intensity, the paper introduces $R$ to denote the relative changing rate of a certain land-use type in a certain period. $R$ is written as:

$R=\frac{\left(\left|N_{a}-N_{b}\right| * M_{a}\right)}{\left(\left|M_{b}-M_{a}\right| * N_{a}\right)}$

In this formula, $N_{a}$ and $N_{b}$ denote the size of a certain land use type in a certain area at the beginning and the end of the study period; $M_{a}$ and $M_{b}$ are the size of a certain land use type in the whole region at the beginning and the end of the same period.

The land use and land cover (LULC) data is obtained from the Landsat TM data 2000 and 2010. Six LULC types were classified for the Bohai Rim region: cultivated land, forested land, grassland, lakes/rivers/ponds, construction land and unused land. Then, land conversion among the different LULC types were measured by rasterizing all LULC vector maps into grids (Li et al., 2010a,b). The employment and industry data refer to the Chinese Counties (Cities) Socio-economic Statistical Yearbook (2000 and 2011) and Chinese Regional Economic Statistical Yearbook (2011).

\section{Results}

The spatial pattern of urban-rural transformation intensity

Fig. 2 shows the urban-rural transformation intensity at the county level in the region in the period 2000-2010. Counties/

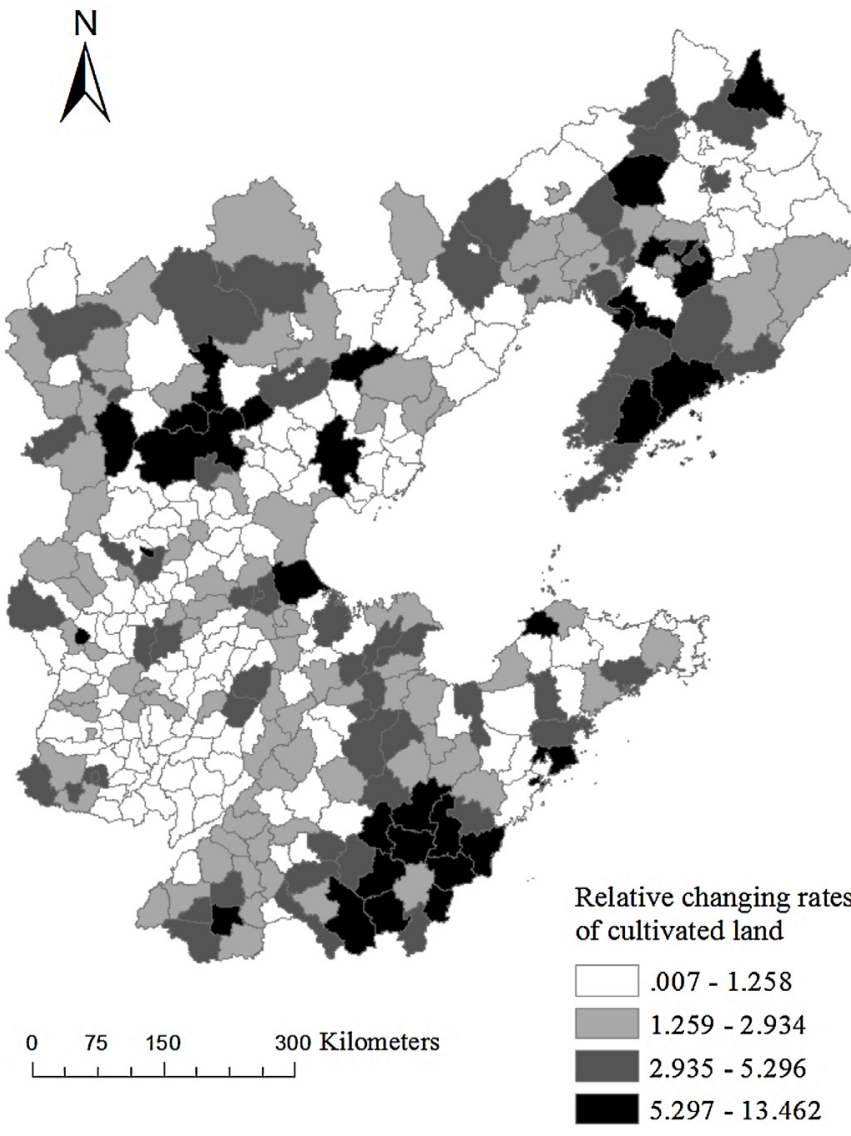

Fig. 3. The relative changing rates of cultivated land at the county level in the Bohai Rim region, 2000-2010.

districts of high transformation intensity are mainly located in the south and southeast parts of Hebei province, south and southwest parts of Shandong province. There are also counties of high transformation intensity, sparsely located in the north and east parts of Hebei province, north part of Liaoning province, suburbs of Beijing and Tianjin. Then, the counties/districts of transformation intensity at the middle level are mostly surrounding the places of high transformation intensity. The central and northwest parts of Hebei province, central parts of Liaoning province, the central areas of Beijing and Tianjin as well as the coastal Tianjin are the places of low transformation intensity.

Basically, places of high urban-rural transformation intensity have major grain production and comparative low socioeconomic development level in the region in 2000. The construction and improvement of transportation system at the beginning of the twenty-first century brought new opportunities and economic stimulus to local development in these areas which experienced drastic urban-rural transformation in the following decade.

Places of low transformation intensity mainly include the urban districts of Beijing, Tianjin and other prefecture-level cities in the region. The central Liaoning and Hebei province used to be the national industrial base where have many industrial projects e.g. steel-making industries constructed there. As a result, urban districts and counties in the industrial areas maintained high urban and rural development level in the years 2000 and 2010. Thus, low intensity of urban-rural transformation took place in these areas during the research period.

Fig. 3 shows the relative changing rates of cultivated land at the county level in the Bohai Rim region in the period 2000-2010. Places of high land changing rates mainly include the central Beijing, south parts of Shandong province and east parts of Liaoning 
Table 2

The average annual changing rates of selected variables among the groups in the Bohai Rim region, 2000-2010.

\begin{tabular}{|c|c|c|c|c|}
\hline \multirow[t]{2}{*}{ Variables } & & \multicolumn{3}{|l|}{ Group } \\
\hline & & Group 1 & Group 2 & Group 3 \\
\hline \multicolumn{2}{|l|}{ Cultivated land conversion $(R)$} & 0.833 & 0.889 & 1.262 \\
\hline \multirow[t]{2}{*}{ Urbanization level } & Initial level (\%) & 41.83 & 17.51 & 15.82 \\
\hline & Changing rates & 0.561 & 1.525 & 1.58 \\
\hline \multirow{2}{*}{$\begin{array}{l}\text { Proportion of non-agricultural } \\
\text { employment }\end{array}$} & Initial level (\%) & 77.93 & 71.92 & 71.68 \\
\hline & Changing rates & 0.957 & 0.972 & 1.074 \\
\hline \multirow{2}{*}{$\begin{array}{l}\text { Proportion of non-agricultural } \\
\text { output value }\end{array}$} & Initial level (\%) & 80.74 & 73.66 & 71.98 \\
\hline & Changing rates & 0.72 & 1.09 & 1.22 \\
\hline
\end{tabular}

province. The areas of land changing rates at middle level are mainly in the southwest, central and north parts of Shandong province, north and east parts of Hebei province as well as some counties in central Liaoning province. Then, most parts of south, central and northeast Hebei province, north and northeast parts of Liaoning province, and east Shandong province are the places of low land changing rates.

By comparing Figs. 3 and 2, inconsistency is found between cultivated land conversion and the urban-rural transformation intensity. For instance, the urban districts of Beijing have low urban-rural transformation intensity, but tend to experience high land changing rates. The north and east parts of Liaoning province have low transformation intensity, however, their land changing rates are low as well. This inconsistency could be attributed to China's land quotas distribution system.

Quotas of new built-up land through requisitioning cultivated land are made annually in China according to the socioeconomic development plans and national land supply policy (Ou et al., 2014). Then, the distribution of the land quotas is made from the central government to each province which distributes the quotas down to the municipalities and counties. In this process, the superior government determines the quantity of land quotas supply for its inferior administrations.

Normally, the superior governments reserve enough quotas for the key projects such as national or provincial infrastructure construction projects. The inferior governments would follow the same way and prioritize land supply for large projects within its own administrative jurisdiction. Thus, land supply for the municipalities like the capital cities, municipal districts and those developed counties could be guaranteed. However, insufficient land quotas are left for many small municipalities, counties and towns which are under the key stages of development. Thus, land quotas shortage has to a large extent, prohibited the urban-rural transformation in many counties of the Bohai Rim region when the central government has tightened the quotas supply in recent years. Then, counties, urban districts and towns within a municipal jurisdiction may not get enough land quotas for local development. In this sense, there would be a priority order of land supply directed and determined by each municipal government (Ou et al., 2014; Liu et al., 2013).

The relationship between cultivated land conversion and urban-rural transformation intensity

According to the above analysis, the paper conducts a $K$-means cluster analysis for each municipality in the Bohai Rim region. Cluster analysis of the urban-rural transformation intensity of all the counties and municipal districts in the region shows a natural break that divides all the counties/districts in each municipality into three groups in the research period (Fig. 4).

The group 1 includes the major urban districts of the municipalities in the region, such as the urban districts of Beijing, Tianjin and the provincial capital cities Shi Jiazhuang, Shenyang and Jinan. Besides, the other counties in group 1 are mainly located in the

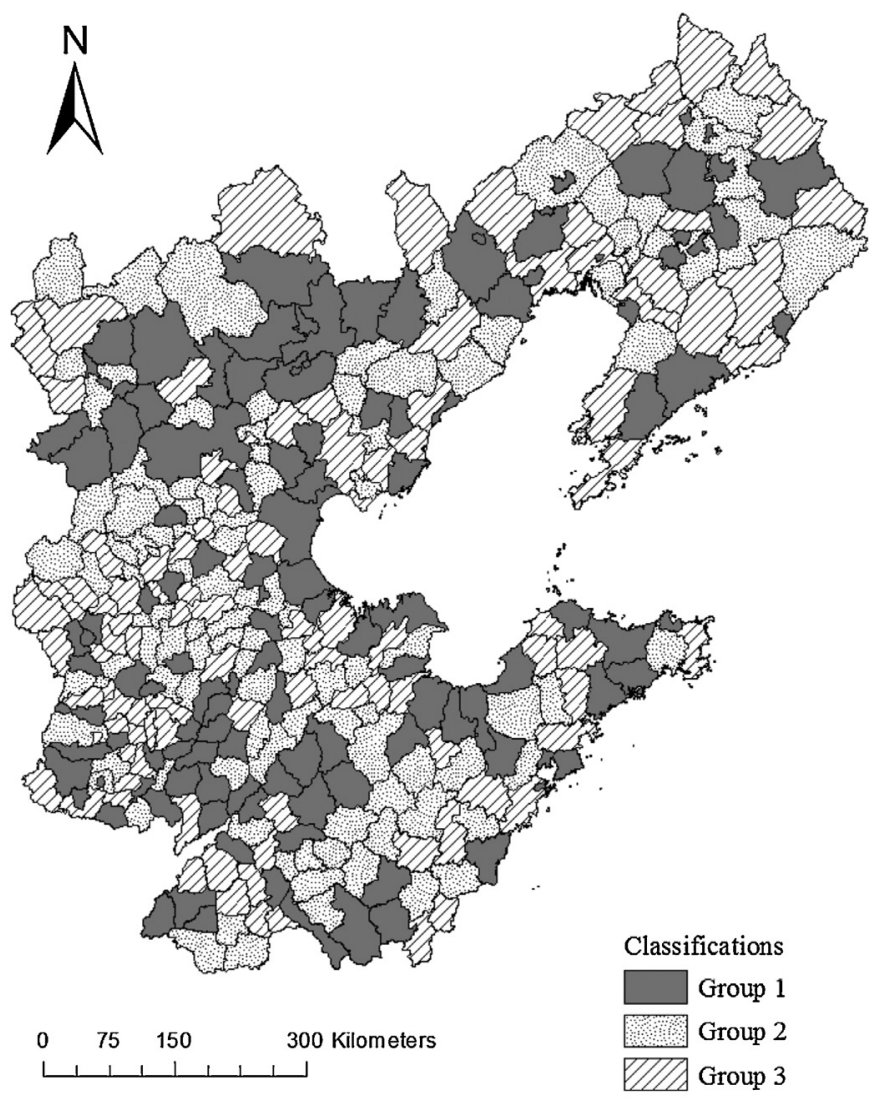

Fig. 4. The classifications of counties/districts in each municipality in the Bohai Rim region.

north and south parts of Hebei province, north parts of Shandong province. Group 2 consists of counties/districts in the central and east parts of Hebei province, central places of Shandong province and the central places of Liaoning province. Counties/districts in the group 3 are sparsely distributed in the region. The suburbs of each municipality, north and south parts of Liaoning province, south and east parts of Shandong province, south and central parts of Hebei province have counties/districts included in the group 3.

Table 2 presents the changing attributes of the three groups in the Bohai Rim region in the period 2000-2010. Evident changing differences of the selected variables among the three groups are seen in the table. First, the group 3 has highest land annual changing rates followed by the group 2 and group 1 . Second, the initial levels of the three aspects of urban-rural transformation in the group 1 are higher than that in the group 2 and group 3. But, the changing rates of the three variables in the group 3 are higher than that in the group 2 and group 1 . The comparison analysis indicates that rapid cultivated land conversion normally takes place in counties/districts of low initial level of urban-rural transformation, 

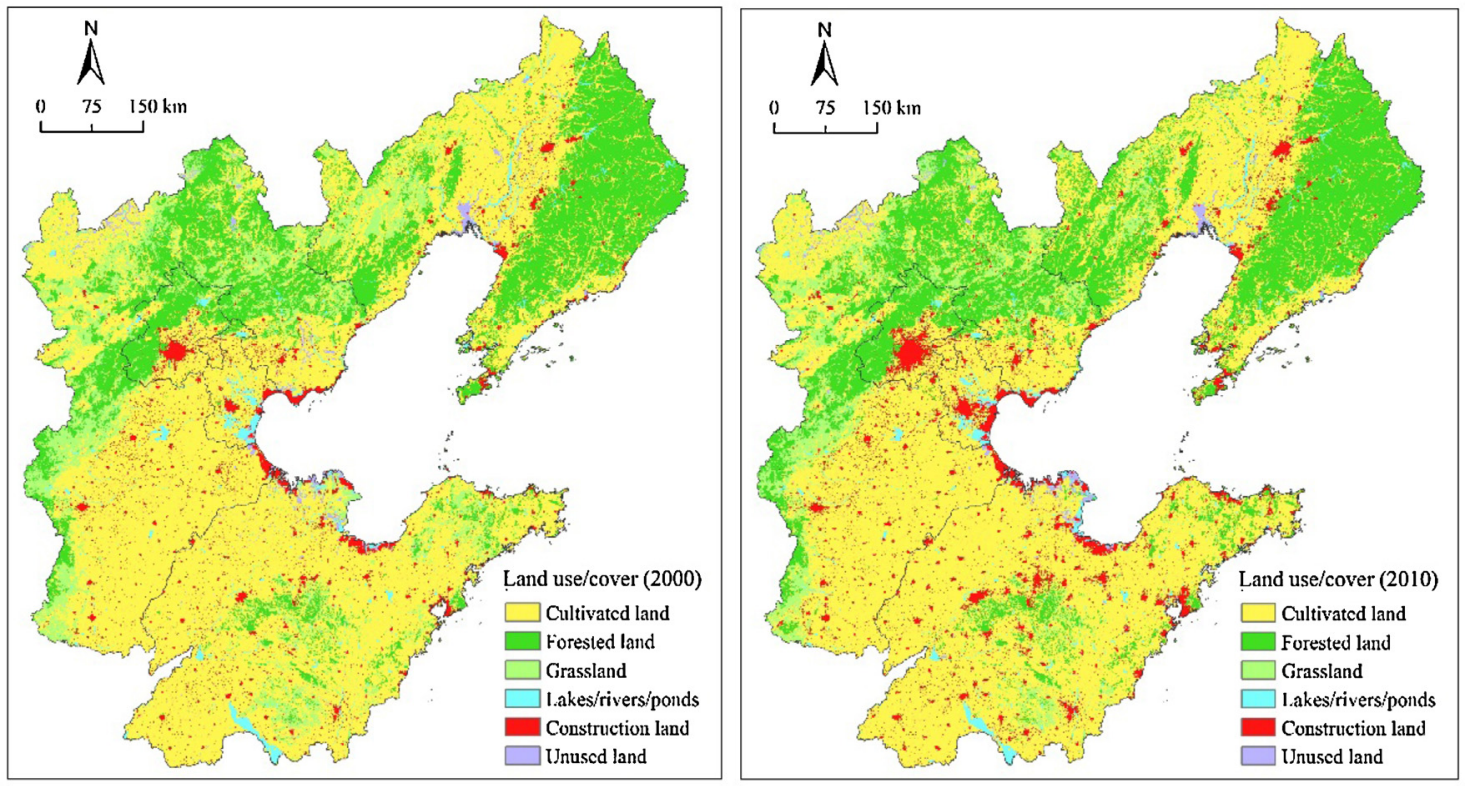

Fig. 5. Land use and land cover change in the Bohai Rim region, 2000 and 2010.

Table 3

Regression analysis of the land conversion rates and urban-rural transformation intensity.

\begin{tabular}{llll}
\hline \multirow{2}{*}{ Variables } & Groups & & \\
\cline { 2 - 4 } & Group 1 & Group 2 & Group 3 \\
\hline Standardized coefficients & 0.162 & 0.151 & 0.094 \\
$t$-Value & 1.681 & 1.802 & 1.704 \\
Sig. & 0.096 & 0.065 & 0.089 \\
\hline
\end{tabular}

Dependent variable: cultivated land conversion rates.

but high transformation intensity. As for those urban districts and their adjacent places, they may have obtained enough land quotas which highly supported their socioeconomic development. Then, when local development reached high level, land conversion rate may drop as the industrial structure shifts from the secondary to the tertiary sectors.

According to the regression results in Table 3, positive relationship between cultivated land conversion rates and the urban-rural transformation intensity exists among the three groups. This indicates that places of high land conversion rates are normally in areas of high urban-rural transformation intensities.

Fig. 5 shows the land use change in the Bohai Rim region in the period 2000-2010. By comparing with the red spots in the years 2000 and 2010, the construction land expansion by requisitioning cultivated land are mainly located in the suburbs of Beijing, Tianjin, Shi Jiazhuang, Jinan, Shenyang and other large municipalities. Then, the south parts of Liaoning province, central and south parts of Hebei province, central, south and east parts of Shandong province are also seen having the major cultivated land conversion in the research period. Basically, the comparison of cultivated land conversion in Fig. 5 proves the relationship between land conversion and urban-rural transformation intensity revealed by the empirical analysis.

\section{Conclusion and discussion}

Positive relationship between land conversion rates and urban-rural transformation intensities is found at the county level in the Bohai Rim region in the period 2000-2010. Generally, counties/districts of low initial level of urban-rural transformation tend to experience drastic land conversion in the following years. However, places of high initial socioeconomic level and low transformation intensity would experience slow land conversion. The major urban districts and the adjacent areas of each municipality such as Beijing, Tianjin and the provincial capital cities like Shi Jiazhuang, Shenyang and Jinan have reached high level of socioeconomic development and their land conversion rates are low in the research period. Counties/districts in the agricultural regions and mountainous areas normally have high urban-rural transformation intensity which resulted in rapid land conversion.

Basically, the different land conversion rates in relation to urban-rural transformation intensity are mainly attributed to the China's land quotas distribution system. According to the "Measures for the Administration of Annual Plans on the Utilization of Land" (Tudi Liyong Niandu Jihua Guanli Banfa), the annual land quotas are made and distributed from the superior to the inferior governments. However, such distribution system normally prioritizes land demand for areas of municipal districts, urban suburbs and places of big development potentialities. For counties in remote mountainous areas and traditional agricultural zones, their land demand may not be guaranteed due to the limited land quotas. As a result, the socioeconomic development in the prioritized areas would first reach high level than those lagging-behind areas. Then, regional inequalities between counties/districts with enough land supply and those with insufficient land supply would also be induced. In this sense, the current land distribution system which is subjective and administrative, is not efficient as expected (Liu et al., 2013; Kong et al., 2014).

The research findings call for an adjusted land quotas distribution system to improve the land distribution efficiency and achieve balanced regional development in China. First, counties/districts of low socioeconomic development level are at the starting or liftoff stages. Their land demand should be satisfied for infrastructure construction, key industrial projects, public services and residential use. Second, intensive land use pattern should be promoted since land use inefficiency is also seen in those well developed areas which have obtained enough land quotas from the superior governments. In sum, controlling the total land quotas supply and coordinated land distribution between the developed and developing areas are necessary in China. The adjusted land distribution system based on the socioeconomic development differences could 
help to curb excessive cultivated land conversion, improve the land use efficiency and achieve balanced regional development in China in the future.

\section{Acknowledgement}

This work was supported by the National Natural Science Foundation of China under Grant nos. 41130748, 41301190 and 41201176.

\section{References}

Cloke, P., Goodwin, M., Milbourne, P., 1997. Rural Wales: Community and Marginalization. University of Wales Press, Cardiff.

Ding, C.R., 2003. Land policy reform in China: assessment and prospects. Land Use Policy 20 (2), 109-120.

Deng, J.S., Wang, K., Hong, Y., Qi, J.G., 2009. Spatio-temporal dynamics and evolution of land use change and landscape pattern in response to rapid urbanization. Landscape Urban Plann. 92 (3-4), 187-198.

Harris, J., 1982. Rural Development: Theories of Peasant Economy and Agrarian Change. Hutchinson, London.

Hoggart, K., Paniagua, A., 2001. What rural restructuring? J. Rural Stud. 17, 41-62.

Johnson, M.P., 2001. Environmental impacts of urban sprawl: a survey of the literature and proposed research agenda. Environ. Plann. 33 (4), 717-735.

Jolly, C.L., Torrey, B.B., 1993. Population and Land Use in Developing Countries. National Academy Press, Washington, DC.

Kong, W., Guo, J., Ou, M.H., 2014. Study on land intensive use response on economic development and regional differentiated control of constructed land. China Popul. Resour. Environ. 24 (4), 100-106.

Li, Y.H., Westlund, H., Cars, G., 2010a. Future urban-rural relationship in China: comparison in a global context. China Agric. Econ. Rev. 2 (4), 396-411.

Li, Y.H., 2011a. The complexity of urban transformation in China: new trends in current transitional era. A|Z J. ITU Fac. Archit. 1 (8), 155-168.

Li, Y.H., 2011b. Urban-rural interaction in China: historic scenario and assessment. China Agric. Econ. Rev. 3 (3), 335-349.

Li, Y.H., 2012a. Urban-rural interaction patterns and dynamic land use: implications for urban-rural integration in China. Reg. Environ. Change 4 (12), 803-812.

Li, Y.H., 2012b. Resource flows and the decomposition of regional inequality in Beijing-Tianjin-Hebei Metropolitan Region, 1990-2004. Growth Change 43 (2), 335-357.

Li, Y.H., Chen, C., Wang, Y.F., Liu, Y.S., 2014. Urban-rural transformation and farmland conversion in China: the application of the environmental Kuznets curve. J. Rural Stud. 36, 311-317.

Li, Y.R., Long, H.L., Liu, Y.S., 2010b. Industrial development and land use/cover change and their effects on local environment: a case study of Changshu in eastern coastal China. Front. Environ. Sci. Eng. 4 (4), 438-448.

Lin, G.C.S., 2010. Understanding land development problems in globalizing China. Eurasian Geogr. Econ. 51 (1), 80-103.
Liu, W.J., 2006. Focus on over land non-agriculturalization in China. China Land 8, 26-27 (in Chinese).

Liu, Q., Ou, M.H., Sheng, Y.X., et al., 2013. Analysis on regional differentiated allocation of construction land: with Jiangsu Province for example. China Popul. Resour. Environ. 23 (12), 119-124.

Liu, Y.S., Liu, Y., Zhai, R.X., 2009. Geographical research and optimizing practice of rural hollowing in China. Acta Geogr. Sin. 64 (10), 1193-1202 (in Chinese).

Liu, Y.S., Fang, F., Li, Y.H., 2014a. Key issues of land use in China and implications for policy making. Land Use Policy 40, 6-12.

Liu, J.Y., Kuang, W.H., Zhang, Z.X., et al., 2014b. Spatio-temporal characteristics, patterns and causes of land-use changes in China since the late 1980. J. Geogr. Sci. 24 (2), 195-210.

Long, H.L., Li, Y.R., Liu, Y.S., 2009. Analysis of evolutive characteristics and their driving mechanism of hollowing villages in China. Acta Geogr. Sin. 64 (10), 1203-1213 (in Chinese).

Long, H.L., Li, Y.R., Liu, Y.S., Woods, M., Zou, J., 2012. Accelerated restructuring in rural China fueled by increasing vs. decreasing balance land-use policy for dealing with hollowed villages. Land Use Policy 29 (1), 11-22.

McGee, T.G., 2008. Managing the rural-urban transformation in East Asia in the 21st century. Sustainability Sci. 3, 155-167.

Mitsuda, Y., Ito, S., 2011. A review of spatial-explicit factors determining spatial distribution of land use/land-use change. Landscape Ecol. Eng. 7 , 117-125.

National Bureau of Statistics of China, 2010. Chinese Statistics Yearbook. China Statistics Press, Beijing.

Njegac, D., Toskic, A., 1999. Rural diversification and socio-economic transformation in Croatia. GeoJournal 46, 263-269.

Peng, K.L., 2008. Social Welfare Effect of Rural-urban Land Conversion: Based on the Equity and Efficiency Theory. Huazhong Agricultural University, Huazhong (in Chinese). (Ph.D. Dissertation).

Ou, S.B., Nong, F.S., Chen, L.G., 2014. Discriminative managing construction land: theoretical explanation and empirical research-take Guangxi Beibu Gulf Economic Zone as an example. China Land Sci. 28 (1), 26-32 (in Chinese).

Roberts, B.R., 1978. Cities of Peasants: The Political Economy of Urbanization in the Third World. Edward Arnold, London.

Robinson, G.M., 2004. Geographies of Agriculture: Globalisation, Restructuring and Sustainability. Pearson, Harlow.

Tacoli, C., 1998. Rural-urban interactions: a guide to the literature. Environ. Urban. 10 (1), 147-165.

Wasilewski, A., Krukowski, K., 2004. Land conversion for suburban housing: a study of urbanization around Warsaw and Olsztyn, Poland. Environ. Manage. 34 (2), 291-303.

White, G., 1998. Development States in East Asia. Macmillan, London.

Woods, M., 2005. Rural Geography: Processes, Responses and Experiences in Rural Restructuring. Sage, London.

Woods, M., 2011. Rural. Routledge, Abingdon and New York, NY.

World Bank, 1993. The East Asian Miracle: Public Policy and Economic Growth Oxford University Press, New York, NY.

Yang, H., Li, X., 2000. Cultivated land and food supply in China. Land Use Policy 17 (2), 73-88.

Zhang, X., Chen, J., Tan, M., Sun, Y., 2007. Assessing the impact of urban sprawl on soil resources of Nanjing city using satellite images and digital soil databases. CATENA 69 (1), 16-30. 